\title{
Localization of polyhydroxybutyrate in sugarcane using Fourier-transform infrared microspectroscopy and multivariate imaging

Jason S. Lupoi ${ }^{1,2,6^{*}}$, Andreia Smith-Moritz², Seema Singh ${ }^{2,3}$, Richard McQualter ${ }^{4,5}$, Henrik V. Scheller ${ }^{2}$, Blake A. Simmons ${ }^{1,2,3}$ and Robert J. Henry ${ }^{1}$

\begin{abstract}
Background: Slow-degrading, fossil fuel-derived plastics can have deleterious effects on the environment, especially marine ecosystems. The production of bio-based, biodegradable plastics from or in plants can assist in supplanting those manufactured using fossil fuels. Polyhydroxybutyrate (PHB) is one such biodegradable polyester that has been evaluated as a possible candidate for relinquishing the use of environmentally harmful plastics.

Results: PHB, possessing similar properties to polyesters produced from non-renewable sources, has been previously engineered in sugarcane, thereby creating a high-value co-product in addition to the high biomass yield. This manuscript illustrates the coupling of a Fourier-transform infrared microspectrometer, equipped with a focal plane array (FPA) detector, with multivariate imaging to successfully identify and localize PHB aggregates. Principal component analysis imaging facilitated the mining of the abundant quantity of spectral data acquired using the FPA for distinct PHB vibrational modes. PHB was measured in the chloroplasts of mesophyll and bundle sheath cells, acquiescent with previously evaluated plant samples.
\end{abstract}

Conclusion: This study demonstrates the power of IR microspectroscopy to rapidly image plant sections to provide a snapshot of the chemical composition of the cell. While PHB was localized in sugarcane, this method is readily transferable to other value-added co-products in different plants.

Keywords: Infrared imaging, Focal plane array, Polyhydroxybutyrate, Sugarcane, Multivariate imaging

\section{Background}

The use of plastics has become ubiquitous in almost every facet of our lives due to low cost and versatile properties. The majority of plastics are obtained from fossil fuels, and as the price of crude oil continues to fluctuate, the price of plastics that are produced from oil feedstocks are expected to oscillate as well (http://articles.ides.com/oil.asp). Fossil fuel-derived plastics also degrade slowly in the environment producing deleterious effects, most notably in marine environments [1-3]. The need to find price-stable sources of plastic resin and to overcome the environmental

\footnotetext{
* Correspondence: jslupoi@lbl.gov

'Queensland Alliance for Agriculture and Food Innovation, University of

Queensland, St. Lucia, Queensland 4072, Australia

${ }^{2}$ Joint BioEnergy Institute, Lawrence Berkeley National Laboratory, 5885 Hollis Street, Emeryville, CA 94608, USA

Full list of author information is available at the end of the article
}

problems is driving the search for bio-renewable, biodegradable plastics.

Polyhydroxybutyrate (PHB) is a biodegradable polyester which possesses similar physical properties to many petroleum-derived plastics [4]. PHB is generated naturally by micro-organisms as a form of energy storage during stress [5]. The biosynthetic pathway for PHB production has been isolated and used for the large-scale manufacture of PHB by fermentation. However, the high production cost of $\mathrm{PHB}$ produced by fermentation and the price of starting substrate pose significant drawbacks [6]. An alternative is to engineer PHB production in plants, which as autotrophs provide their own substrate and energy for PHB production in the form of carbon dioxide, water, and sunlight. The manufacturing of PHB as a value-added co-product in plants, particularly high-biomass-yielding crops such as sugarcane, switchgrass, and maize, has the potential to

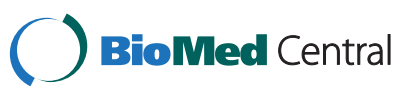


improve the economics of their use for bio-plastic fabrication $[7,8]$. PHB has been successfully engineered in a number of plant species [9] and has potential applications not only as a bio-plastic but also for the manufacture of chemicals and improved animal feed [9-13].

The best results thus far in high-biomass grasses have been obtained by engineering PHB synthesis to the chloroplast $[9,14-16]$. PHB production in the chloroplasts of $\mathrm{C}_{4}$ grasses resulted in polymer formation in all types of leaf cells, as identified by microscopic visualization of granules, with the exception of mesophyll cells where no or only few PHB granules were observed [16]. Strategies to increase polymer production in high-biomass grasses have included the use of stronger constitutive promoters [15], simultaneous overexpression of photosynthesis-related genes [9], as well as modification of the PHB biosynthetic pathway [16]. Although all of these strategies have increased polymer content, only the latter managed to utilize the full capacity of mesophyll cells. Because the spatial distribution of PHB within the sugarcane leaf is crucial to achieving high yields, a robust tool for quantifiably mapping the localization of PHB within the leaf would be of great value.

The physical presence of PHB granules in bacteria [17] and plants [18] has traditionally been detected by Nile Blue A staining. Nile Blue A staining is used in histology to highlight the distinction between neutral lipids which stain pink and acids which stain blue. When a 450-nm excitation wavelength was applied, the PHB granules stained with Nile Blue A showed a strong orange fluorescence (Fig. 1). While the technique is useful for screening for the presence of PHB granules in plant cells, it often produces false positives when polymer levels are low, due to its non-specificity [15]. To the untrained eye, waxy deposits on the leaf surface can often be mistaken for PHB granules. Subcellular localization of PHB granules within plant cells using microscopic imaging can also be problematic due to the intense fluorescence produced by the Nile Blue A polymer interaction, and researchers typically resort to transmission electron microscopy (TEM) for fine resolution of PHB subcellular localization.

Fourier-transform infrared (FTIR) microspectroscopy has proven to be a valuable and more readily available asset for identifying and localizing molecules of interest in plants [19-23]. Cell wall polysaccharides, amides, and aliphatic polyesters were measured in Arabidopsis thaliana petals using a FTIR microspectrometer equipped with an array mercury-cadmium-telluride detector [22]. The coupling of FTIR imaging and second derivative IR spectra revealed distinctive chemical regions such as larger quantities of aliphatic compounds and esters in the lamina, higher proportions of polysaccharides relegated to the petal stalks, and increased hemicellulosic content in the petal hinge. This instrument also enabled the differentiation of diverse mutant Arabidopsis plants. The use of multichannel focal plane array (FPA) detectors has not only decreased the time required to obtain highresolution images but also allowed this imaging technique to be widely available due to the fact that measurements can be done without synchrotron sources. In addition, the technique does not require the sample to be moved on an $x-y$ translation stage, as in IR point-mode mapping, resulting in better reproducibility. Secondary xylem in poplar and Arabidopsis were evaluated using a $64 \times 64$ FPA detector that simultaneously generated 4096 spectra [19]. The combination of this significant amount of spectral data with orthogonal projection to latent structures, a multivariate technique used to elucidate and characterize vital spectral differences using all spectral information, revealed details regarding the chemical plasticity and lignin composition at the cell level that could not have been determined using standard biochemical methods.

In the current study, a FTIR microspectrometer equipped with a $128 \times 128$ FPA detector was used to evaluate wildtype and PHB-containing sugarcane. This detector is capable of simultaneously generating 16,384 infrared spectra. Multivariate imaging, using principal component analysis (PCA), was used to evaluate all of the vibrational modes contained in the spectral data to hone in on the specific differences between the native and modified sugarcane.

\section{Results and discussion}

The motivation of this proof-of-concept research was to evaluate whether FTIR microspectroscopy coupled with multivariate imaging could be a valuable tool for the localization of PHB in sugarcane leaves. Poly $[(R)$-3-hydroxybutyric acid] was commercially obtained and functioned

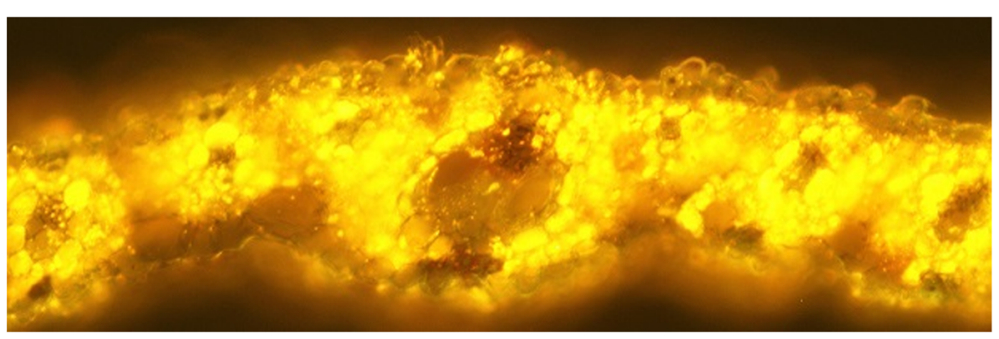

Fig. 1 Example of the fluorescence generated when Nile Blue A staining is used to visualize lipids inside sugarcane 


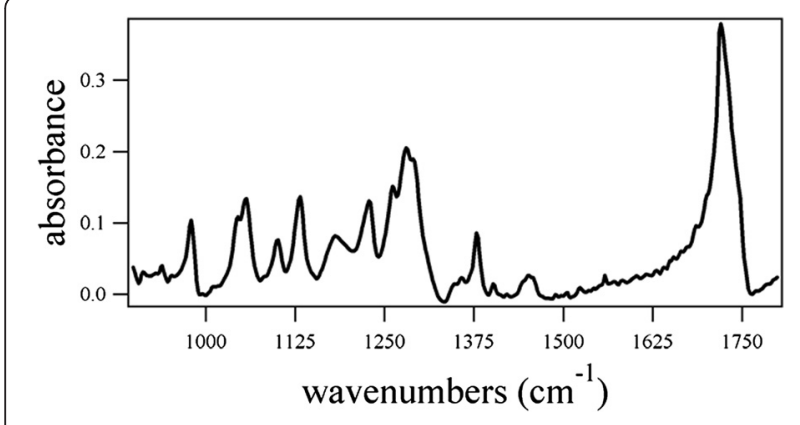

Fig. 2 Fourier-transform infrared spectrum of poly[(R)-3-hydroxybutyric acid]. Vibrational modes and spectral assignments are provided in Table 1. The spectrum was collected using 256 scans and a $128 \times 128$ focal plane array detector

as a standard to aid in identifying vibrational modes that could provide markers to elucidate which peaks in the spectra of the sugarcane corresponded to PHB. Figure 2 shows the FTIR spectrum of PHB, and the experimental vibrational modes and spectral assignments obtained from previous PHB research are provided in Table 1.

Figures $3 \mathrm{a}$ and $4 \mathrm{a}$ provide bright-field images of wildtype and PHB sugarcane, respectively. One of the powerful features of this instrumental configuration is the ability to obtain single-point spectral data for any point in the acquired image. The images depicted by Figs. $3 \mathrm{~b}$ and $4 \mathrm{~b}$ illustrate the use of selecting regions to generate discrete spectra from diverse regions of the plant cross section, including xylem tissue, mesophyll, and a cell vacuole. The

Table 1 Poly[(R)-3-hydroxybutyric acid] vibrational modes and spectral assignments

\begin{tabular}{ll}
\hline Vibrational mode $\left(\mathrm{cm}^{-1}\right)$ & Spectral assignment \\
\hline 979 & $\mathrm{C}=\mathrm{C}[31]$ \\
1045 & $\mathrm{C}-\mathrm{CH}_{3}$ stretching [32] \\
1056 & $\mathrm{C}-\mathrm{O}$ stretching [32] \\
1101 & $\mathrm{C}-\mathrm{O}-\mathrm{C}$ stretching [32] \\
1131 & $\mathrm{CH}_{3}$ rocking [32] \\
1182 & $\mathrm{C}-\mathrm{O}-\mathrm{C}$ stretching [32, 33] \\
1228 & $\mathrm{C}-\mathrm{O}-\mathrm{C}$ stretching [32, 33], $\mathrm{CH}_{2}$ wagging [31] \\
1262 & $\mathrm{C}-\mathrm{O}-\mathrm{C}$ stretching $+\mathrm{CH}_{\text {deformation [32, 33] }}$ \\
1271 & $\mathrm{C}-\mathrm{O}-\mathrm{C}$ stretching (amorphous) [32] \\
1280 & $\mathrm{C}-\mathrm{O}-\mathrm{C}$ stretching (crystalline) [32, 33] \\
1290 & $\mathrm{CH}$ deformation [32] \\
1356 & $\mathrm{CH}$ deformation and $\mathrm{CH}_{3}$ symmetric \\
1378 & deformation [32] \\
1456 & $\mathrm{CH}$ symmetric deformation [32] \\
1720 & $\mathrm{CH}$ scissoring, CH ${ }_{3}$ asymmetric deformation [32] \\
1747 & $\mathrm{C}=\mathrm{O}$ stretch (crystalline) [32-34] \\
\hline
\end{tabular}

analysis of these images and the corresponding spectral data (Fig. 5) from the points selected exposed significant distinctions. The cross-sectional bright-field images of wild-type and PHB sugarcane in Figs. 3a and 4a revealed dark, mesophyll regions. The representative spectra from the PHB sugarcane sample (Fig. 5b) showed a $\mathrm{C}=\mathrm{O}$ stretching mode near $1720 \mathrm{~cm}^{-1}$, which was also measured as the strongest peak in the PHB standard (Fig. 2). While this peak is not of equivalent intensity in the spectrum of wild-type sugarcane, vibrational modes corresponding to $\mathrm{C}=\mathrm{O}$ stretching in lignin and acetyl groups in hemicellulose have been previously measured (Table 2). Therefore, although the intensity of this peak in the PHB sugarcane spectra is conceivably due to PHB, the analysis of other key vibrational modes is necessary. Additional analyses of the peaks in the spectra from the dark regions in the PHB sugarcane samples revealed that each peak corresponded with the expected vibrational modes identified in the PHB standard spectrum. These peaks include the following: In the PHB sugarcane leaf tissue, plausible PHB spectra were identified in mesophyll chloroplasts (Figs. $3 \mathrm{~b}$ and 4b, black and purple circles and corresponding spectra in Fig. 5) but not in xylem tissue (Figs. 3b and 4b, blue dot and Fig. 5, blue spectrum). This concurs with previous observations based on Nile Blue A staining and TEM of PHB sugarcane leaf tissue which shows PHB localized to mesophyll chloroplasts but not xylem tissue [15, $16,24]$. Nile Blue A staining, however, is a general lipid stain and is not specific to PHB. Identification of analytes of interest can be hindered by the strong fluorescence generated, causing overexposure of the image (Fig. 1).

A recently published manuscript discussed the ramifications of the localization of PHB in non-optimal sugarcane cell types [25]. The authors found that PHB produced in bundle sheath chloroplasts interfered with adenosine triphosphate (ATP) production and also affected the Calvin cycle. The use of FTIR microspectroscopy, juxtaposed to the less precise Nile Blue A staining, would have allowed the semi-quantitation of the amount of PHB being produced inside of the bundle sheath chloroplasts across a range of different transgenic plants that produced various levels of PHB. This quantitation would have enabled the determination of the threshold at which PHB hinders ATP in bundle sheath chloroplasts. The data generated from FTIR microspectroscopy could have been used to evaluate the efficiency of different strategies aimed at shifting PHB production from undesirable or detrimental cell types to locales better suited for this type of biomaterial production. Because the bundle sheath chloroplasts can tolerate a certain amount of PHB accumulation before ATP production is compromised [25], various plant promoters could be used, together with FTIR microspectroscopy, to identify the optimal ratio for sharing $\mathrm{PHB}$ production between bundle sheath and mesophyll 
A

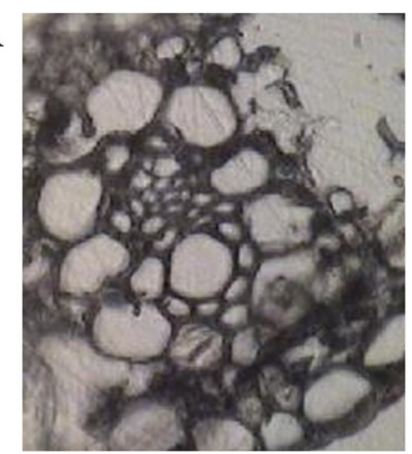

C

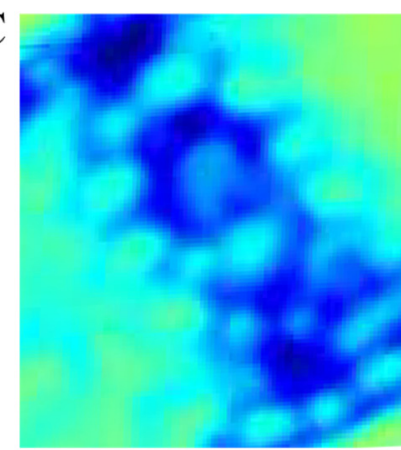

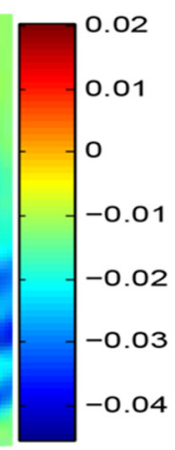

B

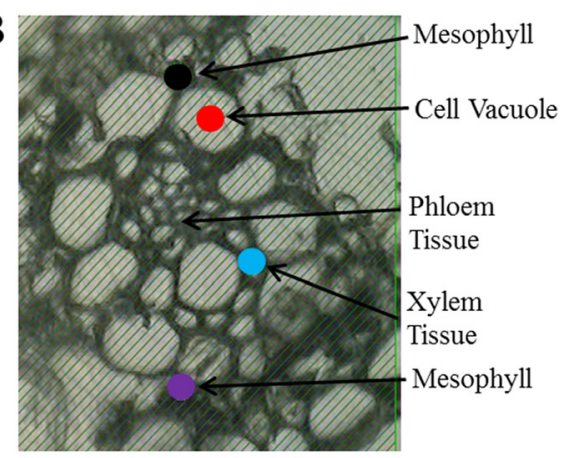

D 0.2

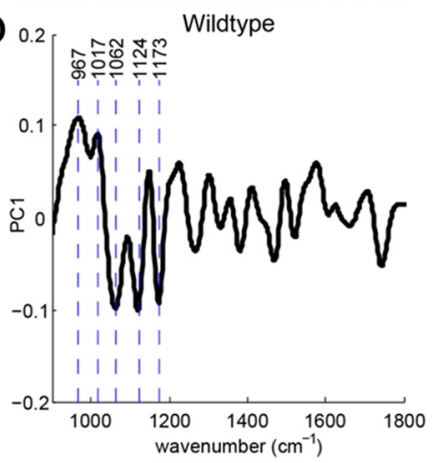

Fig. 3 Images of wild-type sugarcane a without and $\mathbf{b}$ with spectral points selected. The points in image (b) correspond to the wild-type spectra in Fig. 5a. The images were collected using a $128 \times 128$ focal plane array detector. c Re-constructed image using the first principal component. $\mathbf{d}$ Loadings plot for the first principal component used in re-constructing the image in (c)

A

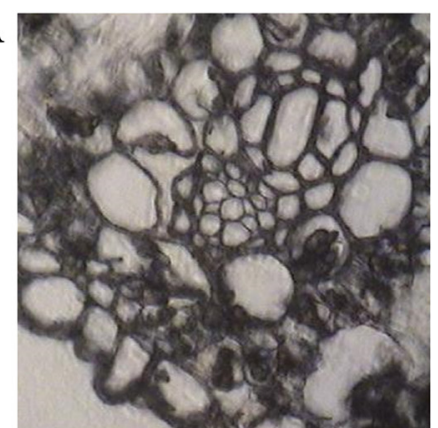

$\mathrm{C}$

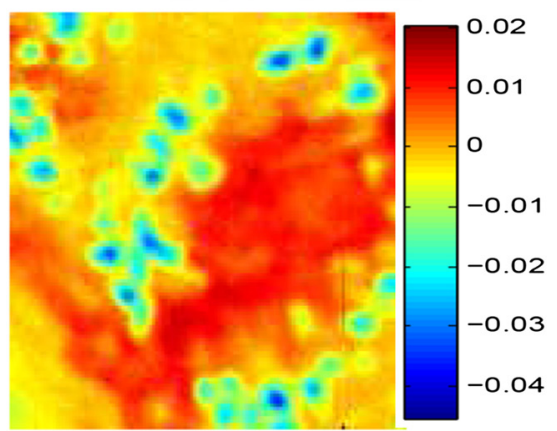

B
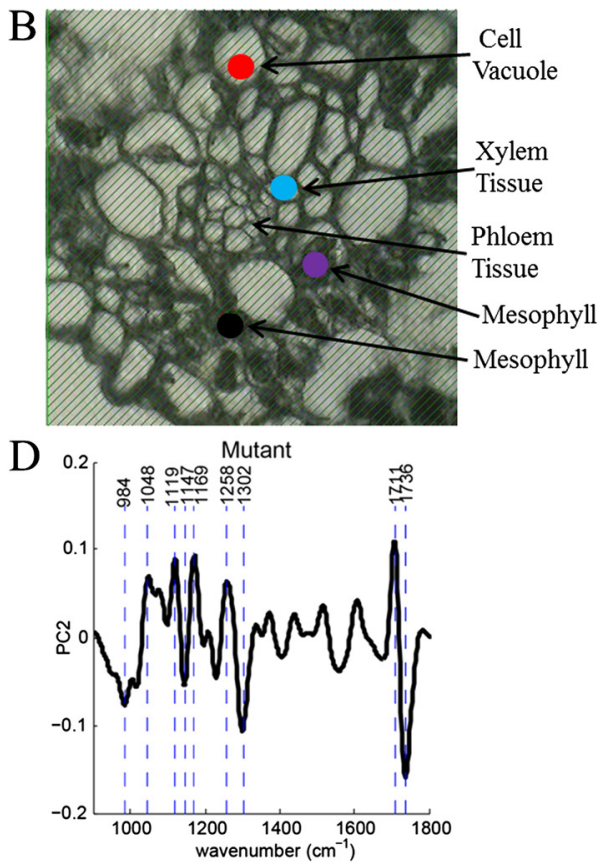

Fig. 4 Images of polyhydroxybutyrate-containing sugarcane $\mathbf{a}$ without and $\mathbf{b}$ with spectral points selected. The points in image b correspond to the PHB sugarcane spectra in Fig. 5b. The images were collected using a $128 \times 128$ focal plane array. c Re-constructed image using the second principal component. $\mathbf{d}$ Loadings plot for the second principal component used in re-constructing the image in (c) 


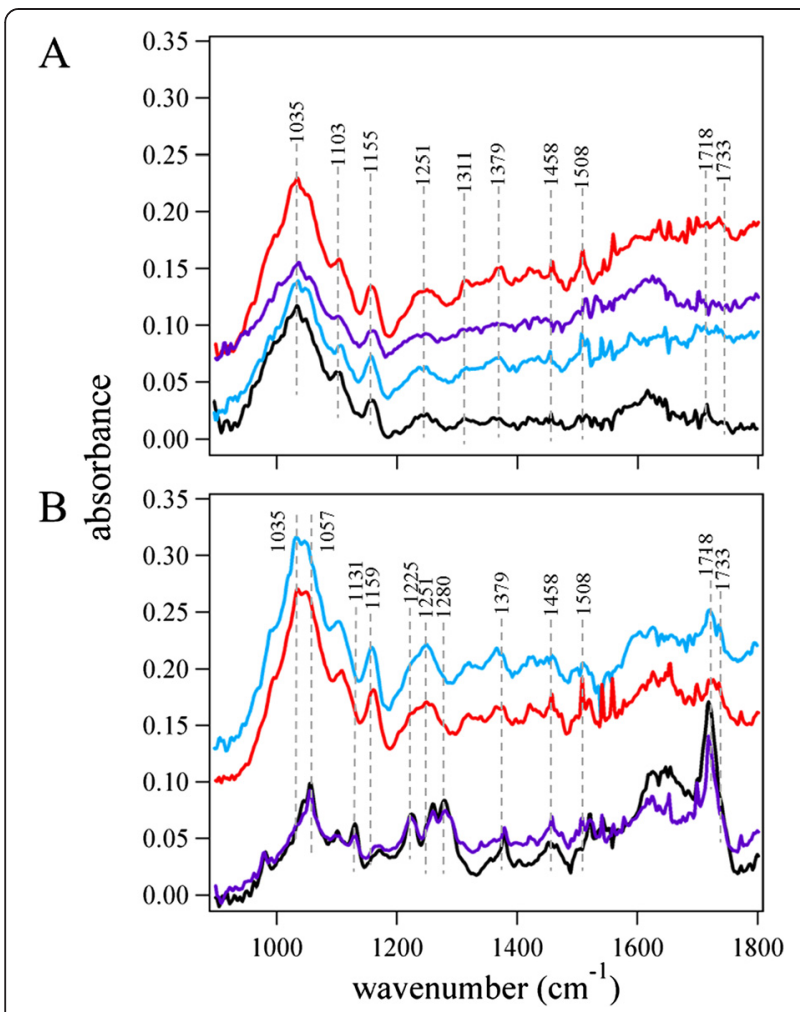

Fig. 5 a Infrared spectra of wild-type sugarcane corresponding to the regions identified by the colored circles in Fig. $3 \mathrm{~b}$. $\mathbf{b}$ Infrared spectra of polyhydroxybutyrate-containing sugarcane corresponding to the regions identified by the colored circles in Fig. 4b. The red spectrum was spatially offset to facilitate a qualitative spectral analysis. All spectra were collected using 256 scans

chloroplasts and thus optimize PHB yield and biomass. This is just one example of how this technique can aid in the production of better biomaterials.

In order to characterize the differences between wildtype and PHB-containing sugarcane, unsupervised multivariate analysis was employed. The use of PCA alleviated the need to integrate specific PHB peaks that may be obscured by other cell constituents, particularly cell wall polysaccharides, by assessing all spectral information. Additionally, integrating the area under a specific peak requires spectral processing, such as baseline correction or normalization. These transformations can artificially alter the data if not carefully performed. To eliminate spectral variations such as baseline offsets, without needing to perform baseline corrections, the first derivatives were calculated for all spectra and were used in the PCA. The resulting principal component $(\mathrm{PC})$ scores were then plotted according to spatial coordinates, generating images reflecting the major features contributing to specific PC loadings. The first $12 \mathrm{PC}$ scores and loadings representing approximately $90 \%$ of the variation in the samples were plotted and evaluated for the wild-type and PHBcontaining sugarcane cross sections (data not shown). It must be noted that following the transformation of raw spectral data to the corresponding first derivative, there is a slight shift of the vibrational mode location along the $x$ axis. This is due to the calculation of the first derivative, as the raw peak maxima are now located at zero. The shifted vibrational modes can still be interpreted analogously to the complementary raw spectral data.

Figure 3c shows the heat map for the first PC scores and loadings, determined from the wild-type sugarcane first derivative spectra. Figure $3 \mathrm{~d}$ provides the complementary loadings plot for this PC, which enabled the identification of the specific vibrational modes paramount to re-constructing the original image. Peaks near $967 \mathrm{~cm}^{-1}$ (arabinoxylan) [26], $1016 \mathrm{~cm}^{-1}$ (pectin) [27], $1062 \mathrm{~cm}^{-1}$ (glycoside linkage in cellulose) [28], $1123 \mathrm{~cm}^{-1}(\mathrm{C}-\mathrm{O}$ and C-C stretching in starch) [29], and $1173 \mathrm{~cm}^{-1}$ (xylan) [30] were identified from the first derivative IR spectra as being especially useful in producing the heat map. In comparison with the native sugarcane sample, sugarcane containing $\mathrm{PHB}$, the heat maps (Fig. 4c) and loadings plot (Fig. 4d) corresponding to the second PC revealed distinctively different integral vibrational modes. The loadings plot illustrated that the PCA was converging on peaks particular to PHB. This can be further visualized by overlaying the first derivative spectrum of the PHB standard with the first and second PCs (Fig. 6a, b, respectively). Again, these vibrational modes are slightly shifted, compared to the raw spectral peaks provided in Tables 1 and 2 , due to the first derivative transformation. Therefore, the first derivative PHB spectrum has been overlaid with the loadings of PC1 (Fig. 6a) and PC2 (Fig. 6b) to facilitate the analysis of the loadings. It is clear from this appraisal that the first PC, which explains $34.6 \%$ of the spectral variance, is drawing out the 1069,1709 , and $1743 \mathrm{~cm}^{-1} \mathrm{PHB}$ peaks, with other peaks at 972 and $1020 \mathrm{~cm}^{-1}$ indicative of cell wall constituents such as arabinoxylan and cellulose. The second PC, explaining $24.9 \%$ of the spectral variance, however, seems to be honing in more directly to the PHB vibrational modes: 1122, 1142, 1172, 1227, 1258, $1302,1365,1435,1708$, and $1739 \mathrm{~cm}^{-1}$. Given the chemical complexity of plant samples and despite the $4 \mathrm{~cm}^{-1}$ spectral resolution, some of these peaks may overlap with those generated by other cell wall constituents. For example, the raw vibrational modes listed in Table 2 reveal lignin and hemicellulose peaks near 1716, 1722, and 1739 $\mathrm{cm}^{-1}$. The raw spectral data generated from specific plant organelles shown in Fig. 5 reveals that these $\mathrm{C}=\mathrm{O}$ vibrational modes, although present, do not have considerable spectral intensities relative to the intense $\mathrm{C}=\mathrm{O}$ stretch in $\mathrm{PHB}$. Overlapping spectral bands necessitate the consideration of all vibrational modes being drawn out by a specific PC. The analysis of PCs beyond the first two did not prove to be useful in classifying the wild-type or PHB sugarcane samples. 
Table 2 Sugarcane cell wall vibrational modes and spectral assignments

\begin{tabular}{|c|c|}
\hline Vibrational mode $\left(\mathrm{cm}^{-1}\right)$ & Spectral assignment \\
\hline 967 & Arabinoxylan [26] \\
\hline 991 & C-O stretch [35] \\
\hline 1006 & $\mathrm{C}-\mathrm{O}$ and $\mathrm{C}-\mathrm{C}$ stretch, and $\mathrm{CH}_{2}$ rock in cellulose [36] \\
\hline 1016 & Pectin [27] \\
\hline 1026 & $\mathrm{C}-\mathrm{O}, \mathrm{C}-\mathrm{O}-\mathrm{H}, \mathrm{C}-\mathrm{O}-\mathrm{C}, \mathrm{C}-\mathrm{C}$, ring stretching vibration in cellulose and hemicellulose $[30,37,38]$ \\
\hline \multirow[t]{2}{*}{1035} & Aromatic C-H in-plane deformation (lignin) $[19,39] ;$ \\
\hline & $\mathrm{C}-\mathrm{C}, \mathrm{C}-\mathrm{O}, \mathrm{C}-\mathrm{C}-\mathrm{O}, \mathrm{C}-\mathrm{O}-\mathrm{C}, \mathrm{C}-\mathrm{O}-\mathrm{H}$ stretch in cellulose and hemicellulose $[19,37,40,41]$ \\
\hline 1040 & $\mathrm{C}-\mathrm{C}, \mathrm{C}-\mathrm{O}, \mathrm{C}-\mathrm{O}-\mathrm{C}, \mathrm{C}-\mathrm{O}-\mathrm{H}$ stretching vibration in cellulose and hemicellulose $[19,37]$ \\
\hline 1053 & C-O stretch, C-O, C-C ring $[19,41]$ \\
\hline 1062 & Glycosidic linkage in cellulose [28] \\
\hline \multirow[t]{2}{*}{1104} & $\mathrm{C}-\mathrm{O}-\mathrm{H}, \mathrm{C}-\mathrm{O}-\mathrm{C}, \mathrm{C}-\mathrm{C}$, ring stretching vibration in cellulose $[19,37,41]$ \\
\hline & OH band in cellulose and hemicellulose $[19,38,41]$ \\
\hline 1110 & O-H band in cellulose and hemicellulose (crystalline cellulose); cellulose anti-symmetrical stretch [35] \\
\hline 1123 & C-O, C-C stretching in starch [29] \\
\hline \multirow[t]{2}{*}{1159} & $\mathrm{C}-\mathrm{C}, \mathrm{C}-\mathrm{O}, \mathrm{C}-\mathrm{O}-\mathrm{C}, \mathrm{C}-\mathrm{O}-\mathrm{H}$ stretching vibration in cellulose $[19,37,40-42]$; \\
\hline & Anti-symmetrical bridge oxygen stretching [35] \\
\hline 1173 & C-O-C, C-C stretch in xylan [30] \\
\hline \multirow[t]{2}{*}{1249} & Aryl ring breathing mode; $\mathrm{C}-\mathrm{O}$ stretch (lignin) $[19,35,41]$; \\
\hline & C-O stretch in hemicelluloses $[19,41,42]$ \\
\hline 1315 & $\mathrm{C}-\mathrm{H}$ ring, $\mathrm{CH}_{2}$ symmetrical wagging, $\mathrm{O}-\mathrm{H}$ in-plane bending $[19,35,42]$ \\
\hline 1339 & $\mathrm{O}-\mathrm{H}$ in-plane bending and $\mathrm{CH}$ in cellulose and hemicellulose $[35,40,42]$ \\
\hline \multirow[t]{2}{*}{1374} & $\mathrm{C}-\mathrm{H}$ bending in cellulose $[35]$; \\
\hline & $\mathrm{C}-\mathrm{H}, \mathrm{CH}_{2}$ bending in hemicellulose $[19,41]$ \\
\hline \multirow[t]{2}{*}{1419} & $\mathrm{CH}_{2}$ scissoring at $\mathrm{C}(6)$ in cellulose [38]; \\
\hline & $\mathrm{C}-\mathrm{H}$ deformation in hemicellulose $[19,41]$ \\
\hline \multirow[t]{2}{*}{1458} & O-H in-plane bending in cellulose [35]; \\
\hline & $\mathrm{CH}_{3}$ asymmetrical bending (lignin) $[19,39,41]$ \\
\hline 1497 & Aromatic ring vibration [43] \\
\hline 1509 & $C=C$ stretching vibration in aromatic ring of lignin $[19,38,39,41]$ \\
\hline 1541 & $\mathrm{~N}-\mathrm{H}$ in amide $\|[44,45]$ \\
\hline 1639 & $\mathrm{C}=\mathrm{C}$, conjugated or aromatic carbonyl groups [46] \\
\hline 1647 & C-O stretching vibration in lignin [41] \\
\hline 1716 & $\mathrm{C}=\mathrm{O}$ stretch in lignin [19] \\
\hline 1722 & $C=O$ stretch in lignin $[19]$ \\
\hline 1733 & $\mathrm{C}=\mathrm{O}$ stretching vibration in acetyl groups of hemicellulose $[38,40-42]$ \\
\hline
\end{tabular}

\section{Conclusions}

FTIR microspectroscopy coupled with multivariate imaging provides a powerful analytical tool for understanding plant cell ultrastructure and enables the localization of intrinsic or exogenously added molecules of interest. In this study, PHB was identified in mesophyll and bundle sheath chloroplasts. Earlier analyses of these PHBexpressing plants have relied upon staining with Nile Blue to locate the PHB. However, this stain is not specific for PHB as it is a general lipid stain. The IR method used here allows much more specific localization of $\mathrm{PHB}$ within the cells and tissues of the plant. For example, very specific expression in plastids is indicated by the IR method. FTIR microspectroscopy also has advantages over TEM, as the instrumentation is cheaper and less complex and does not require more experienced researchers to prepare and analyze the samples. Other components of the plant cell can also be localized using this instrumental technique, such as cellulose, hemicelluloses, and lignin, although the signal obtained from 

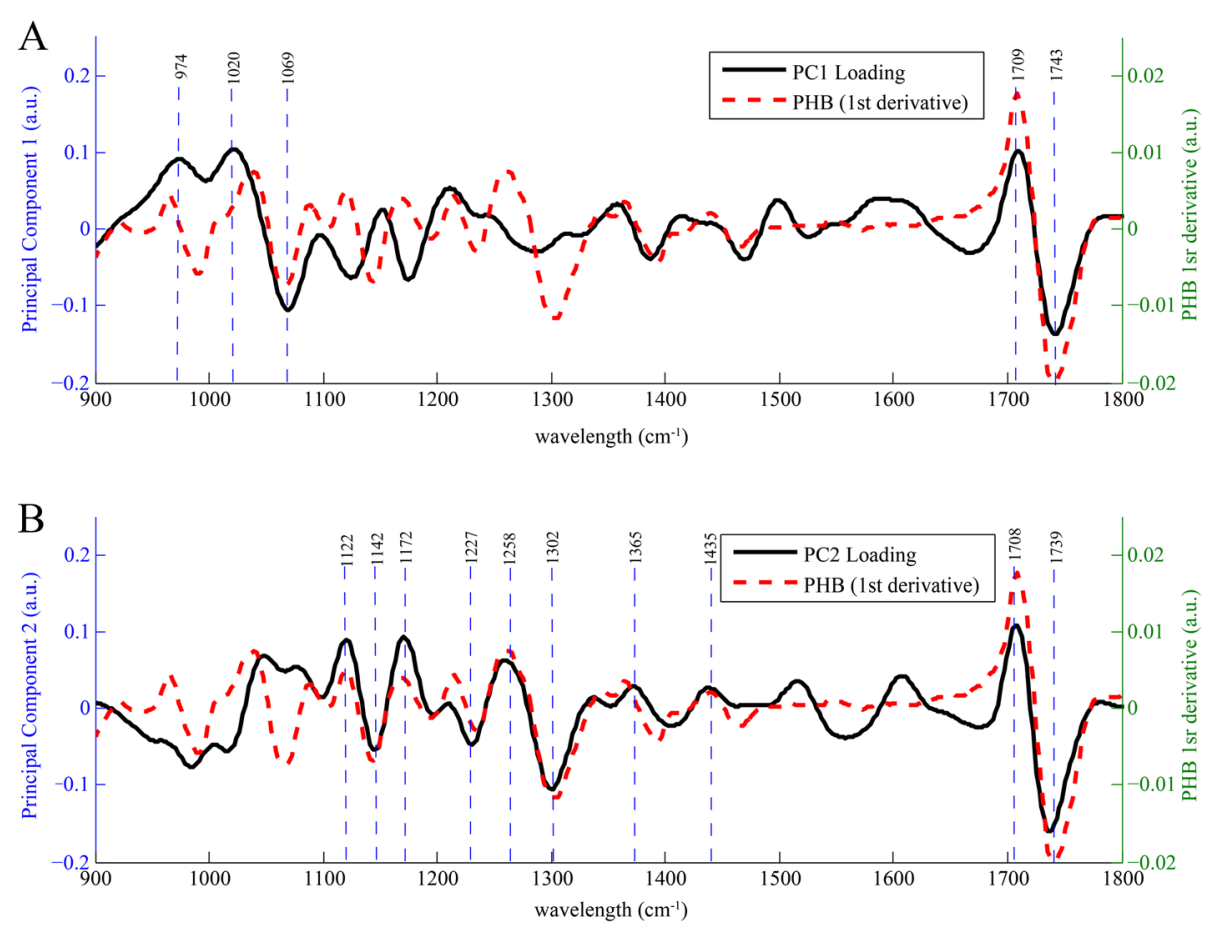

Fig. 6 a First derivative spectrum of sugarcane containing PHB overlaid with the first principal component. b First derivative spectrum of sugarcane containing PHB overlaid with the second principal component

lignin vibrational modes can be rather weak when infrared excitation sources are used.

\section{Methods}

\section{Sugarcane samples}

The polyhydroxybutyrate-producing sugarcane line NBC37 used in this study has been previously described [16]. NBC37 and wild-type sugarcane plants of cultivar Q117 were grown to maturity in large pots containing a commercial potting mix, under glasshouse conditions at the University of Queensland, Brisbane, Australia. Fully developed whole leaf material was collected and dried in an oven at $70{ }^{\circ} \mathrm{C}$ for $48 \mathrm{~h}$.

\section{Plant sectioning}

Prior to sectioning the sugarcane, leaf samples were embedded in Tissue-Tek O.C.T. Compound (Sakura-Finetek, Torrance, CA, USA). The samples were placed in the embedding media such that a cross section of the leaf was obtained. Additional media was spiraled around the sugarcane samples such that the sample was completely enveloped.

The plant sections were obtained using a Leica CM3050$\mathrm{S}$ cryostat (Leica, Buffalo Grove, IL, USA). The temperature of the cryostat was set to $-28{ }^{\circ} \mathrm{C}$, while the sample thickness was fixed at $5 \mu \mathrm{m}$. The samples were affixed to standard glass microscope slides (VWR International, West Chester, Pennsylvania, USA). The O.C.T. Compound was removed from the slide by incubating the slide in a Petri dish containing deionized water, until the media was solubilized, and the sections were detached from the microscope slide. The sugarcane samples were then removed from the Petri dish using a pipette with a wide-orifice tip and placed onto optically transparent calcium fluoride windows (International Crystal Labs, Garfield, NJ, USA). The samples were put inside of a desiccator overnight to remove residual water.

\section{Fourier-transform infrared microspectroscopy}

The FTIR imaging instrument consisted of a Bruker Hyperion 3000 infrared microscope (Bruker Corporation, Billerica, MA, USA) coupled with a Bruker Tensor 27 FTIR spectrometer (Bruker Corporation, Billerica, MA, USA). The microscope was equipped with a liquid nitrogen cooled, $128 \times 128$ pixel, focal plane array (FPA) detector (model\# SBF161, Santa Barbara Focalplane, Goleta, CA, USA) and a 36x infrared objective. The detector has a pixel size of $40 \mu \mathrm{m}$, which results in a measured area of $1.1 \mu \mathrm{m}$ per pixel. This number is the pixel resolution of the image. Using the $36 \times$ objective, the imaged area is approximately $142 \mu \mathrm{m}$ per frame. Multiple frames were employed to provide a larger image of the sugarcane cross section. The instrumental signal was optimized prior to collecting the spectra and images by subtly re-aligning the beam path such that the maximum available signal was used. All spectral data was collected using 256 scans and a spectral resolution of $4 \mathrm{~cm}^{-1}$. The 
cross-sectional images were obtained, using transmission mode, after $14 \mathrm{~min}$ of analysis time. Poly[ $(R)$-3-hydroxybutyric acid] (Sigma-Aldrich, St. Louis, MO, USA) was measured to identify possible vibrational modes that could be used as markers for the detection of PHB inside the sugarcane cross sections. The spectral data was imported into IGOR Pro V 6.1 (WaveMetrics Inc., Lake Oswego, OR, USA) for further analysis and plotting.

\section{Multivariate imaging}

The first derivatives of the spectra were calculated using a Savitzky-Golay filter and 17 point smoothing. This was done to remove baseline correction issues that could occur with varying sample thickness across the plant cross sections. The data were also mean-centered. PCA was then used for data compression, and the resulting principal component (PC) scores were individually plotted according to spatial coordinates, generating an image based on each PC. All data processing was performed using custom scripts run on Matlab (Mathworks, Natick, MA, USA).

\section{Abbreviations}

FPA: focal plane array; FTIR: Fourier-transform infrared; PC: principal component; PCA: principal component analysis; PHB: polyhydroxybutyrate; TEM: transmission electron microscopy.

\section{Competing interests}

The authors declare that they have no competing interests.

\begin{abstract}
Authors' contributions
JSL performed the sectioning and imaging of the sugarcane samples. ASM performed the multivariate analysis of the spectral data. SS conceived the project. RM engineered the sugarcane samples containing PHB and helped write the manuscript. HVS, BAS, and RJH provided guidance and support during this research. All authors read and approved the final manuscript.
\end{abstract}

\section{Acknowledgements \\ This manuscript was supported as part of collaboration between the University of Queensland and the Joint BioEnergy Institute. The work conducted by the Joint BioEnergy Institute was supported by the Office of Science, Office of Biological and Environmental Research of the US Department of Energy under contract no. DE-AC02-05CH11231. The authors would like to thank Steve Ruzin and Denise Schichnes, at the CNR Biological Imaging Facility at the University of California-Berkeley, for the assistance with and use of the Leica cryotome, and Shunlin Wang of Bruker Optics, Inc., Fremont, CA, for providing guidance related to the Bruker FTIR Tensor instrument.

\footnotetext{
Author details

${ }^{1}$ Queensland Alliance for Agriculture and Food Innovation, University of Queensland, St. Lucia, Queensland 4072, Australia. ${ }^{2}$ Joint BioEnergy Institute, Lawrence Berkeley National Laboratory, 5885 Hollis Street, Emeryville, CA 94608, USA. ${ }^{3}$ Biological and Engineering Sciences Center, Sandia National Laboratories, 7011 East Avenue, Livermore, CA 94551, USA. ${ }^{4}$ Australian Institute for Bioengineering and Nanotechnology, University of Queensland, St. Lucia, Queensland 4072, Australia. ${ }^{5}$ Department of Biological Sciences, University of North Texas, 1155 Union Circle \#305220, Denton, TX 76203, USA. ${ }^{6}$ Sage Analytics, Boulder, CO 80301, USA.
}

Received: 16 February 2015 Accepted: 26 June 2015

Published online: 10 July 2015

\section{References}

1. Holmes LA, Turner A, Thompson RC. Adsorption of trace metals to plastic resin pellets in the marine environment. Environ Pollut. 2012;160(1):42-8. doi:10.1016/j.envpol.2011.08.052.

2. O'Brine T, Thompson RC. Degradation of plastic carrier bags in the marine environment. Mar Pollut Bull. 2010;60(12):2279-83. doi:10.1016/ j.marpolbul.2010.08.005.

3. Derraik JG. The pollution of the marine environment by plastic debris: a review. Mar Pollut Bull. 2002;44(9):842-52.

4. Steinbüchel A, Hofrichter M. Biopolymers. Weinheim. Chichester: Wiley-VCH; 2001.

5. Hankermeyer CR, Tjeerdema RS. Polyhydroxybutyrate: plastic made and degraded by microorganisms. Rev Environ Contam Toxicol. 1999;159:1-24.

6. J-i C, Lee SY. Process analysis and economic evaluation for poly(3hydroxybutyrate) production by fermentation. Bioprocess Eng 1997;17(6):335-42.

7. Snell KD, Peoples OP. PHA bioplastic: a value-added coproduct for biomass biorefineries. Biofuel Bioprod Bior. 2009;3(4):456-67. doi:10.1002/Bbb.161.

8. van Beilen JB, Poirier Y. Plants as factories for bioplastics and other novel biomaterials. In: Altman A, Hasegawa PM, editors. Plant biotechnology and agriculture: prospects for the 21st century. London, UK: Academic; 2012. p. 463-506.

9. Somleva MN, Peoples OP, Snell KD. PHA bioplastics, biochemicals, and energy from crops. Plant Biotechnol J. 2013;11(2):233-52. doi:10.1111/ pbi.12039.

10. Mullen CA, Boateng AA, Schweitzer D, Sparks K, Snell KD. Mild pyrolysis of $\mathrm{P} 3 \mathrm{HB} /$ switchgrass blends for the production of bio-oil enriched with crotonic acid. J Anal Appl Pyrolysis. 2014;107:40-5.

11. Gao X, Chen J-C, Wu Q, Chen G-Q. Polyhydroxyalkanoates as a source of chemicals, polymers, and biofuels. Curr Opin Biotechnol. 2011;22(6):768-74. doi:10.1016/j.copbio.2011.06.005.

12. Lee SY, Lee Y, Wang F. Chiral compounds from bacterial polyesters: sugars to plastics to fine chemicals. Biotechnol Bioeng. 1999;65(3):363-8. doi:10.1002/(SICI)1097-0290(19991105)65:3<363::AID-BIT15>3.0.CO;2[--]1.

13. Schweitzer D, Mullen CA, Boateng AA, Snell KD. Biobased n-butanol prepared from poly-3-hydroxybutyrate: optimization of the reduction of n-butyl crotonate to n-butanol. Org Process Res Dev. 2014. doi:10.1021/ op500156b.

14. Poirier Y, Gruys KJ. Production of polyhydroxyalkanoates in transgenic plants. In: Doi Y, Steinbuchel A, editors. Biopolymer. Berlin: Wiley-VHC; 2001. p. 401-35.

15. Petrasovits LA, Zhao L, McQualter RB, Snell KD, Somleva MN, Patterson NA, et al. Enhanced polyhydroxybutyrate production in transgenic sugarcane. Plant Biotechnol J. 2012;10(5):569-78. doi:10.1111/j.1467-7652.2012.00686.X.

16. McQualter RB, Gebbie LK, Xuemei L, Petrasovits LA, Snell KD, Nielsen LK, et al. Factors affecting polyhydroxybutyrate accumulation in mesophyll cells of C4 grasses. BMC Biotechnol. 2014;14:83-93.

17. Ostle AG, Holt JG. Nile blue A as a fluorescent stain for poly-beta-hydroxybutyrate. Appl Environ Microbiol. 1982;44(1):238-41.

18. Arai $Y$, Nakashita $H$, Doi $Y$, Yamaguchi I. Plastid targeting of polyhydroxybutyrate biosynthetic pathway in tobacco. Plant Biotechnol J. 2001;18(4):289-93.

19. Gorzsás A, Stenlund H, Persson P, Trygg J, Sundberg B. Cell-specific chemotyping and multivariate imaging by combined FT-IR microspectroscopy and orthogonal projections to latent structures (OPLS) analysis reveals the chemical landscape of secondary xylem. Plant J. 2011;66(5):903-14. doi:10.1111/j.1365-313X.2011.04542.x.

20. Heraud P, Caine S, Sanson G, Gleadow R, Wood BR, McNaughton D. Focal plane array infrared imaging: a new way to analyse leaf tissue. New Phytologist. 2007;173(1):216-25. doi:10.1111/j.1469-8137.2006.01881.x.

21. Marcott C, Reeder RC, Sweat JA, Panzer DD, Wetzel DL. FT-IR spectroscopic imaging microscopy of wheat kernels using a mercury-cadmium-telluride focal-plane array detector. Vibrational Spectroscopy. 1999;19(1):123-9. doi:10.1016/S0924-2031(98)00050-2.

22. Mazurek S, Mucciolo A, Humbel BM, Nawrath C. Transmission Fourier transform infrared microspectroscopy allows simultaneous assessment of cutin and cell-wall polysaccharides of Arabidopsis petals. Plant J. 2013;74(5):880-91. doi:10.1111/tpj.12164.

23. Monti F, Dell'Anna R, Sanson A, Fasoli M, Pezzotti M, Zenoni S. A multivariate statistical analysis approach to highlight molecular processes in plant cell walls through ATR FT-IR microspectroscopy: the role of the 
a-expansion PhEXPA1 in Petunia hybrida. Vibrational Spectroscopy. 2013;65(0):36-43. doi:10.1016/j.vibspec.2012.11.010.

24. Petrasovits LA, Purnell MP, Nielsen LK, Brumbley SM. Production of polyhydroxybutyrate in sugarcane. Plant Biotechnol J. 2007;5(1):162-72. doi:10.1111/j.1467-7652.2006.00229.x.

25. McQualter RB, Bellasio C, Gebbie LK, Petrasovits LA, Palfreyman RW, Hodson MP, et al. Systems biology and metabolic modelling unveils limitations to polyhydroxybutyrate accumulation in sugarcane leaves; lessons for $C_{4}$ engineering. Plant Biotechnol J 2015;1-14. doi:10.1111/pbi.12399.

26. Jamme F, Robert P, Bouchet B, Saulnier L, Dumas P, Guillon F. Aleurone cell walls of wheat grain: high spatial resolution investigation using synchrotron infrared microspectroscopy. Appl Spectrosc. 2008;62:895-900.

27. McCann MC, Hammouri M, Wilson R, Belton P, Roberts K. Fourier transform infrared microspectroscopy is a new way to look at plant cell walls. Plant Physiol. 1992;100(4):1940-7. doi:10.1104/pp. 100.4.1940.

28. Jarvis MC, McCann MC. Macromolecular biophysics of the plant cell wall: concepts and methodology. Plant Physiol Biochem. 2000;38(1-2):1-13.

29. Robert P, Marquis M, Barron C, Guillon F, Saulnier L. FT-IR investigation of cell wall polysaccharides from cereal grains. Arabinoxylan infrared assignment. J Agric Food Chem. 2005;53(18):7014-8. doi:10.1021/jf051145y.

30. Kacurikova M, Wellner N, Ebringerova A, Hromidkova Z, Wilson RH, Belton PS. Characterization of xylan-type polysaccharides and associated cell wall components by FT-IR and FT-Raman spectroscopies. Food Hydrocolloids. 1998;13(1):35-41.

31. Bayari S, Severcan F, Gursel I, Hasirci V, Alaeddinoglu G. The FTIR studies of the poly(3-hydroxybutyrate) and poly(3-hydroxybutyrate-co-3hydroxyvalerate). In: Haris PI, Chapman D, editors. New biomedical materials: basic and applied studies. Amsterdam: Ios Press; 1998. p. 58-64.

32. Furukawa T, Sato H, Murakami R, Zhang J, Duan Y-X, Noda I, et al. Structure, dispersibility, and crystallinity of poly(hydroxybutyrate)/poly(l-lactic acid) blends studied by FT-IR microspectroscopy and differential scanning calorimetry. Macromolecules. 2005;38(15):6445-54. doi:10.1021/ma0504668.

33. Padermshoke A, Katsumoto Y, Sato H, Ekgasit S, Noda I, Ozaki Y. Melting behavior of poly(3-hydroxybutyrate) investigated by two-dimensional infrared correlation spectroscopy. Spectrochim Acta A Mol Biomol Spectrosc. 2005;61(4):541-50. doi:10.1016/.jsaa.2004.05.004

34. Tian G, Wu Q, Sun S, Noda I, Chen G-Q. Two-dimensional Fourier transform infrared spectroscopy study of biosynthesized poly (hydroxybutyrate-co-hydroxyhexanoate) and poly (hydroxybutyrate-co-hydroxyvalerate). J Polym Sci B. 2002;40(7):649-56. doi:10.1002/polb.10126.

35. Liang CY, Marchessault RH. Infrared spectra of crystalline polysaccharides. II. Native celluloses in the region from 640 to $1700 \mathrm{~cm}^{-1}$. J Polym Sci. 1959:39:269-78. doi:10.1002/pol.1959.1203913521.

36. Tsuboi M. Infrared spectrum and crystal structure of cellulose. J Polym Sci. 1957;25(109):159-71. doi:10.1002/pol.1957.1202510904.

37. Kacurakova M, Capek P, Sasinkova V, Wellner N, Ebringerova A. FT-IR study of plant cell wall model compounds: pectic polysaccharides and hemicelluloses. Carbohydr Polym. 2000;43(2):195-203. doi:10.1016/s0144-8617(00)00151-x.

38. Karatzos S, Edye L, Doherty WO. Sugarcane bagasse pretreatment using three imidazolium-based ionic liquids; mass balances and enzyme kinetics. Biotechnol Biofuels. 2012;5(1):62.

39. Faix O. Classification of lignins from different botanical origins by FT-IR spectroscopy. Holzforschung. 1991;45(Suppl, Lignin and Pulping Chemistry):21-7. doi:10.1515/hfsg.1991.45.s1.21.

40. Sills DL, Gossett JM. Using FTIR to predict saccharification from enzymatic hydrolysis of alkali-pretreated biomasses. Biotechnol Bioeng. 2012;109(2):353-62. doi:10.1002/bit.23314.

41. Labbé N, Rials T, Kelley S, Cheng Z-M, Kim J-Y, Li Y. FT-IR imaging and pyrolysis-molecular beam mass spectrometry: new tools to investigate wood tissues. Wood Sci Technol. 2005;39(1):61-76. doi:10.1007/s00226004-0274-0.

42. Akerholm M, Salmén L. Interactions between wood polymers studied by dynamic FT-IR spectroscopy. Polymer. 2001;42(3):963-9. doi:10.1016/50032$3861(00) 00434-1$.

43. Faix O. Fourier transform infrared spectroscopy [of lignin in solid state]. In: Lin SY, Dence CW, editors. Methods in lignin chemistry. Berlin, Germany: Springer-Verlag; 1992. p. 83-109.

44. Machado MD, Janssens S, Soares HMVM, Soares EV. Removal of heavy metals using a brewer's yeast strain of Saccharomyces cerevisiae: advantages of using dead biomass. J Appl Microbiol. 2009;106(6):1792-804. doi:10.1111/j.1365-2672.2009.04170.x.

45. Wang Y, Zhou Q, Li B, Liu B, Wu G, Ibrahim M, et al. Differentiation in MALDI-TOF MS and FTIR spectra between two closely related species Acidovorax oryzae and Acidovorax citrulli. BMC Microbiol. 2012;12(1):182.

46. Nuopponen MH, Wikberg HI, Birch GM, Jaaskelainen A-S, Maunu SL, Vuorinen T, et al. Characterization of 25 tropical hardwoods with Fourier transform infrared, ultraviolet resonance Raman, and 13C-NMR cross-polarization/magic-angle spinning spectroscopy. J Appl Polym Sci. 2006;102(1):810-9. doi:10.1002/app.24143.

\section{Submit your next manuscript to BioMed Central and take full advantage of:}

- Convenient online submission

- Thorough peer review

- No space constraints or color figure charges

- Immediate publication on acceptance

- Inclusion in PubMed, CAS, Scopus and Google Scholar

- Research which is freely available for redistribution

Submit your manuscript at www.biomedcentral.com/submit 